\title{
GABAergic Projections from Lateral Hypothalamus to Paraventricular Hypothalamic Nucleus Promote Feeding
}

\author{
(1)Zhaofei Wu, ${ }^{1 *}$ Eun Ran Kim, ${ }^{1 *}$ Hao Sun, ${ }^{1 *}$ Yuanzhong Xu, ${ }^{1}$ Leandra R. Mangieri, ${ }^{1,2}$ De-Pei Li, ${ }^{3}$ Hui-Lin Pan, ${ }^{3}$ \\ Yong $\mathrm{Xu},{ }^{4}$ Benjamin R. Arenkiel, ${ }^{5}$ and $\mathbb{Q}^{Q}$ ingchun Tong ${ }^{1,2}$ \\ ${ }^{1}$ Brown Foundation Institute of Molecular Medicine and ${ }^{2}$ Graduate Program in Neuroscience of Graduate School of Biological Sciences, University of Texas \\ Medical School at Houston, Houston, Texas 77030, ${ }^{3}$ Division of Anesthesiology and Critical Care, University of Texas M.D. Anderson Cancer Center, \\ Houston, Texas 77030, ${ }^{4}$ Children's Nutrition Research Center, Department of Pediatrics, Baylor College of Medicine, Houston, Texas 77030, and \\ ${ }^{5}$ Department of Neuroscience and Jan Duncan Neurological Research Institute, Baylor College of Medicine, Houston, Texas, 77030
}

Lesions of the lateral hypothalamus ( $\mathrm{LH})$ cause hypophagia. However, activation of glutamatergic neurons in LH inhibits feeding. These results suggest a potential importance for other LH neurons in stimulating feeding. Our current study in mice showed that disruption of GABA release from adult LH GABAergic neurons reduced feeding. LH GABAergic neurons project extensively to the paraventricular hypothalamic nucleus (PVH), and optogenetic stimulation of GABAergic LH $\rightarrow$ PVH fibers induced monosynaptic IPSCs in PVH neurons, and potently increased feeding, which depended on GABA release. In addition, disruption of GABA-A receptors in the PVH reduced feeding. Thus, we have identified a new feeding pathway in which GABAergic projections from the LH to the PVH promote feeding.

Key words: feeding; GABA; LH; optogenetics; PVH

\section{Introduction}

Recent studies have identified important, neuropeptide-expressing hypothalamic neurons that regulate feeding (Luquet et al., 2005; Leinninger et al., 2011; Atasoy et al., 2012; Krashes et al., 2014). However, a large number of neurons that do not express known peptides may also have critical roles in feeding ( $\mathrm{Xu}$ and Tong, 2011). Lesions of the lateral hypothalamus (LH) lead to hypophagia (Bernardis and Bellinger, 1996), suggesting that the net effects of LH neurons are to promote eating. However, it has been recently shown that selective activation of glutamatergic neurons in the LH inhibits feeding (Jennings et al., 2013). These contrasting results suggest a potential importance for other types of $\mathrm{LH}$ neurons in promoting feeding.

Increasing evidence supports an importance for GABA as a neurotransmitter, in mediating feeding behavior. However, the vast majority of previous studies regarding GABA action focus on GABAergic AgRP neurons (Wu et al., 2009; Atasoy et al., 2012;

\footnotetext{
Received Sept. 5, 2014; revised Dec. 18, 2014; accepted Jan. 17, 2015

Author contributions: Z.W., E.R.K., H.S., L.R.M., and Q.T. designed research; Z.W., E.R.K., H.S., Yuanzhong Xu, L.R.M., and D.-P.L. performed research; Yong Xu and B.R.A. contributed unpublished reagents/analytic tools; Z.W., E.R.K., H.S., Yuanzhong Xu, L.R.M., D.-P.L., H.-L.P., and Q.T. analyzed data; E.R.K., H.S., L.R.M., and Q.T. wrote the paper.

This work was supported by National Institutes of Health R01DK092605 and University of Texas Health Brain Initiative and CTSA UL1 TR000371 to Q.T., National Institutes of Health R01DK093587, R00DK085330, P30DK079638-03 to Yong Xu, and National Institutes of Health R01HL077400 to H.-L.P. We thank Dr. Peer Wulff for providing $\gamma 2^{\text {flox/flox }}$ mice.

The authors declare no competing financial interests.

*Z.W., E.R.K., and H.S. contributed equally to this work.

Correspondence should be addressed to Dr. Qingchun Tong, Brown Foundation Institute of Molecular Medicine, University of Texas Medical School at Houston, 1825 Pressler Street, Houston, TX 77030. E-mail: qingchun.tong@uth.tmc.edu.

DOI:10.1523/JNEUROSCI.3720-14.2015

Copyright $\odot 2015$ the authors $\quad 0270-6474 / 15 / 353312-07 \$ 15.00 / 0$
}

Krashes et al., 2013). At the same time, the functions of numerous non-AgRP GABAergic neurons elsewhere in the hypothalamus have not been elucidated. Interestingly, our previous study showed a selective role for GABA release from a subset of Arc GABAergic neurons, which express Cre driven by the rat insulin promoter (Rip-Cre) (Song et al., 2010), in energy expenditure regulation, but not in feeding (Kong et al., 2012), suggesting the importance of nonpeptidergic GABAergic hypothalamic neurons in regulating metabolism. However, the potential role of GABAergic neurons in other hypothalamic sites, including $\mathrm{LH}$, remains largely unknown.

Previous pharmacological studies suggest a role for GABA in the paraventricular nucleus of hypothalamus $(\mathrm{PVH})$ in feeding regulation ( $\mathrm{Pu}$ et al., 1999; Stanley et al., 2011). However, it is unknown whether the GABA action is mediated directly or indirectly by $\mathrm{PVH}$ neurons given the potential widespread diffusion associated with the GABA administration. Further electrophysiological studies suggest that GABA may mediate the effects of NPY on PVH neurons (Melnick et al., 2007), and optogenetic studies demonstrate that GABA release from AgRP neurons onto $\mathrm{PVH}$ neurons directly mediates feeding behavior (Atasoy et al., 2012). However, the physiological relevance of GABA release to $\mathrm{PVH}$ neurons is not clear. Of note, GABA release from AgRP neurons is surprisingly not required for feeding behavior (Krashes et al., 2013), suggesting that other redundant AgRP neural pathways exist for promoting food intake.

We and others have shown that Cre expression driven by the pancreas duodenum homeobox 1 promoter ( $\mathrm{Pdx} 1)$ exhibits abundant expression in the $\mathrm{LH}$ region caudal to the $\mathrm{PVH}$, dorsomedial hypothalamus (DMH), arcuate nucleus, and a few other brain sites (Honig et al., 2010; Song et al., 2010). By taking advantage of this Cre expression, our current study identified a 
potent role of LH GABAergic neurons in promoting feeding through projections to the $\mathrm{PVH}$, in which GABA release is required. Our findings suggest that the physiological function of this projection is to promote nocturnal feeding.

\section{Materials and Methods}

Animal care. Mice were housed at $21^{\circ} \mathrm{C}-22^{\circ} \mathrm{C}$ with a $12 \mathrm{~h}$ light $/ 12 \mathrm{~h}$ dark cycle with food and water provided ad libitum. Animal care and procedures were approved by the University of Texas Health Science Center at Houston Institutional Animal Care and Use Committee. Rip-Cre and Pdx1-Cre mice were described previously (Song et al., 2010). Mice with Cre expression driven by the single-minded 1 gene promoter (Sim1-Cre) were described previously and these mice show Cre expression mainly in the PVH, but also in the other brains sites, including the amygdala and nucleus of lateral olfactory tract (Balthasar et al., 2005). Mice with the conditional allele of vesicular GABA transporter ( $V g a t$, also named Slc32a1) and mice with the conditional allele of GABA-A receptor $\gamma 2$ subunit were reported previously (Wulff et al., 2007; Tong et al., 2008). Breeding pairs (male Pdx1-Cre:Vgat $t^{\text {flox/flox }}$ mice and female Vgat $t^{\text {flox/flox }}$ mice; and male Sim1-Cre: $\gamma 2^{\text {flox/flox }}$ mice and female $\gamma 2^{\text {flox/flox }}$ mice) were maintained to generate the study subjects. Male and female Vgat flox/+ mice were interbred to generate wild-type and $V g a t^{f l o x / f l o x}$ mice for AAVCre injection study described below. In addition, Sim1-Cre mice were bred to Ai9 reporter mice (Madisen et al., 2010) to generate Sim1-Cre:Ai9 mice for electrophysiological recording.

Studies with stereotaxic injections. At the start of surgical procedures, mice were anesthetized with ketamine and xylazine and placed on a stereotaxic frame (David Kopf Instruments). AAV-Cre-GFP vectors were purchased from the viral core facility of the University of Pennsylvania and were stereotaxically injected into bilateral $\mathrm{LH}(50 \mathrm{nl})$ with the following coordinates: bregma $-1.6 \mathrm{~mm}$; midline $\pm 1.0 \mathrm{~mm}$; dorsal surface $-5.1 \mathrm{~mm}$, of wild-type or Vgat $t^{\text {flox/flox }}$ mice using a $0.5 \mu$ l Hamilton syringe controlled by a nano-injector (Stoelting). The injection speed was $0.5 \mathrm{nl} / \mathrm{min}$, and the syringe was withdrawn $15 \mathrm{~min}$ after the final injection. Mice were used for experiments after a 2 week period recovery. We aimed to delete Vgat in the LH region with Pdx1-Cre expression. Because Pdx1-Cre is only expressed in the LH region located caudal to the PVH (Song et al., 2010), we targeted AAV-Cre-GFP to this specific $\mathrm{LH}$ region. To avoid the concern that Vgat deletion in nearby non-LH regions affects feeding, we excluded all mice with obvious AAV-Cre-GFP expression in non-LH regions as defined by Paxinos and Franklin (2004). We scored those mice with AAV-Cre-GFP expression limited to bilateral $\mathrm{LH}$ posterior to the $\mathrm{PVH}$ but across at least $1 \mathrm{~mm}$ in the rostral-caudal dimension of $\mathrm{LH}$ as hit.

In situ hybridization. Then RNAscope Multiple Fluorescent Assay, a novel in situ hybridization technique with a unique "double $Z$ " probe design, which greatly increases signal-to-noise ratio and can visualize RNA transcripts at a single molecular level (Wang et al., 2012; Xu et al., 2013), was used to detect transcripts in the brain (Advanced Cell Diagnostics). Matched LH section from Vgat flox/flox and Pdx1-Cre:Vgat flox/flox mice ( $n=3$ each) were used to estimate percentage of LH neurons with Vgat deletion by Pdx1-Cre.

Food intake measurements. Weekly body weight was monitored in all genotypes fed standard mouse chow (Teklad F6 Rodent Diet 8664, 4.05 $\mathrm{kcal} / \mathrm{g}, 3.3 \mathrm{kcal} / \mathrm{g}$ metabolizable energy, $12.5 \% \mathrm{kcal}$ from fat, Harlan Teklad) from 4 - to 5 - week-old mice. For $24 \mathrm{~h}$ feeding pattern measurements, food intake was determined every hour for $24 \mathrm{~h}$ and averaged for comparison between genotypes.

Immunohistochemistry assays. For immunohistochemistry studies, we used a previously described protocol (Xu et al., 2012). Primary antibody against $\gamma 2$ (NB300-190, Novus Biologicals) was used. Sections were visualized and photographed with a TCS SP5 confocal microscope (Leica). The images from brain sections incubated with the $\gamma 2$ antibody were obtained using an Axioimager fluorescence microscope with Axiocam digital camera (Zeiss) and then exported in grayscale.

Brain slice electrophysiological recordings. Brain slices were prepared from mice (4-6 weeks of age) anesthetized with isoflurane. Coronal brain slices $(350 \mu \mathrm{m})$ were cut in ice-cold artificial CSF (aCSF) contain- ing the following (in mM): $124 \mathrm{NaCl}, 5 \mathrm{KCl}, 1.25 \mathrm{NaH}_{2} \mathrm{PO}_{4}, 1.3 \mathrm{MgSO}_{4}$, $2 \mathrm{CaCl}_{2}, 26 \mathrm{NaHCO}_{3}$, and 11 glucose and adjusted to $\mathrm{pH} 7.4$ by bubbling with $95 \% \mathrm{O}_{2} / 5 \% \mathrm{CO}_{2}$. Slices containing the $\mathrm{PVH}$ and/or $\mathrm{LH}$ were immediately transferred to a holding chamber and submerged in oxygenated aCSF. Slices were maintained for recovery for at least $1 \mathrm{~h}$ at $34^{\circ} \mathrm{C}$ before transferring to a recording chamber. aCSF at $32^{\circ} \mathrm{C}$ was perfused into slice chambers with $\sim 2 \mathrm{ml} / \mathrm{min}$ flow rate regulated by miniplus 3 peristaltic pump (Gilson).

Sim1-Cre-expressing neurons in brain slices from reporter mice were identified by ds-Red fluorescence emission using a custom filter set and then visually targeted with infrared differential interference optics. Evoked IPSCs in Sim1 neurons were also recorded in voltage-clamp using the same internal solution. Stimuli ( $0.1 \mathrm{~ms}$ duration) were applied through bipolar stimulating electrodes (FHC) placed into the surrounding area of the PVH. The stimulus intensity was adjusted to the level (ranging from $100 \mu \mathrm{A}$ to $1 \mathrm{~mA}$ ) at which an evoked current was $\sim 90 \%$ of the amplitude of the maximal response. Kynurenic acid ( $1 \mathrm{~mm}$ ) was used to block glutamate-mediated EPSCs. At the end of experiments, $20 \mu \mathrm{M}$ bicuculline was applied to the bath to confirm the nature of GABA-A receptor-mediated currents. All recordings were made using a Multiclamp 700B amplifier (Molecular Devices), and data were digitized at 10 $\mathrm{kHz}$ and filtered at $2 \mathrm{kHz}$ using pClamp 10.3 (Molecular Devices). Data were analyzed off-line with Clampfit (Molecular Devices) and MiniAnalysis software (Snaptosoft).

Channelrhodopsin 2(ChR2)-assisted circuitry mapping and feeding. The ChR2-assisted circuitry mapping was performed similarly as previously described (Kong et al., 2012). Adeno-associated vectors with Credependent expression of ChR2 and yellow fluorescent protein (YFP), AAV-FLEX-ChR2-YFP (generated by Dr. Ben Arenkiel) (Herman et al., 2014) were delivered to bilateral LH of 6- to 7-week-old male Pdx1-Cre and Pdx1-Cre:Vgat flox/flox mice, and the recordings were performed 2-3 weeks after viral delivery. The same coordinates as described above for AAV-Cre-GFP delivery were used for the viral delivery. IPSCs were recorded from neurons in the posterior $\mathrm{PVH}$ with high $\mathrm{Cl}^{-}$internal solution (in mM: $140 \mathrm{CsCl}, 1$ BAPTA, 10 HEPES, $5 \mathrm{MgCl}_{2}, 5 \mathrm{Mg}$-ATP, 0.3 Na2GTP, and 10 QX-314, pH 7.35). To photostimulate the ChR2expressing fibers, a laser source (473 nm; Opto Engine) was used with 1 $\mathrm{Hz}$ frequency stimulation. A previous estimate shows that all PVH neurons are Sim1-Cre positive (Kublaoui et al., 2008); thus, recording experiments on field stimulation-evoked IPSCs in Sim1 neurons and photostimulation-evoked IPSCs in PVH neurons target the same group of neurons.

For optogenetic feeding studies, an optic fiber cannula was implanted immediately after the completion of AAV-FLEX-ChR2-YFP delivery. The optic fiber cannula $(200 \mu \mathrm{m}$ in diameter and $0.39 \mathrm{NA}$, Thorlabs) was implanted $\sim 0.4 \mathrm{~mm}$ above the posterior PVH with the following coordinates: bregma: $1.0 \mathrm{~mm}$; midline: $0 \mathrm{~mm}$; dorsal surface: $4.8 \mathrm{~mm}$. Targeted expression of AAV-FLEX-ChR2-YFP in LH $\mathrm{Pdx} 1-$ Cre neurons and correct implantation of optic fibers were verified by post hoc examination. Light power was measured by a PM 100D meter with an S121C sensor (Thorlabs). An online program provided by Dr. Deisseroth laboratory at Stanford University (http://web. stanford.edu/group/dlab/cgi-bin/graph/chart.php) was used for estimating the actual light power on local fibers. After a 2 week recovery from surgery, mice were individually housed and regular chow diet was provided in a Petri dish. Fiber optic cables (1.5 m long, $200 \mu \mathrm{m}$ diameter; Thorlabs) were firmly attached to the implanted fiber optic cannula with an opaque mating sleeve. Mice were allowed at least 3-4 d to acclimate before experimental sessions. Blue laser stimulation (473 nm, Opto Engine, light power exiting the fiber tip $3 \mathrm{~mW}$ ) at $20 \mathrm{~Hz}$ with $40 \mathrm{~ms}$ duration for $10 \mathrm{~min}$ generated by Master 8 (AMPI) was used to test feeding levels in early morning (9:00 to 11:00 A.M.), which were compared with the feeding levels during periods of $10 \mathrm{~min}$ before and that after laser stimulation.

Statistical analysis. Data are mean \pm SEM, and comparison between means was performed with an appropriate statistical analysis specified in figure legends, using Prism 6.0 with $p<0.05$ indicating statistical significance. Tukey multiple comparison was used for two-way ANOVA tests. 


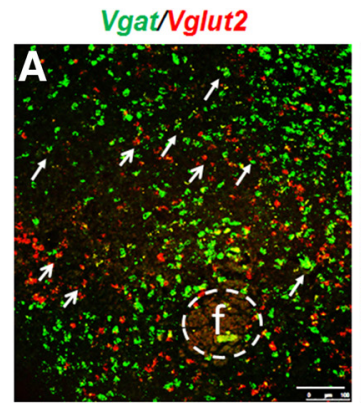

Wild type

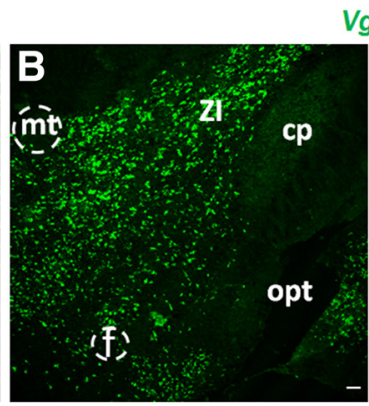

Vgat flox/flox

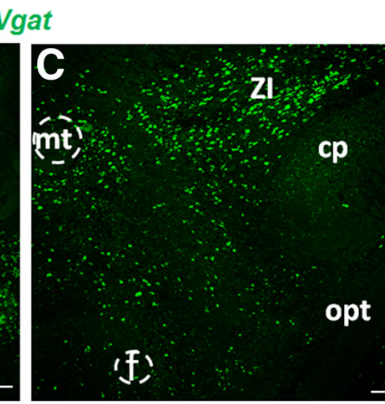

Pdx1-Cre:Vgat flox/flox

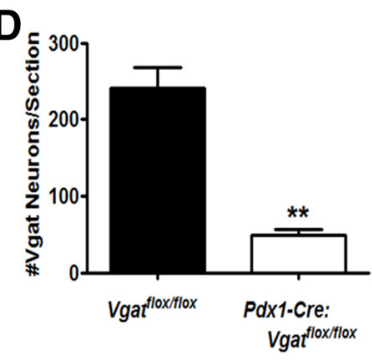

Vgat floxfllox

Figure 1. Vgat and Vglut2 expression in the LH. $\boldsymbol{A}$, Vgat (green) and Vglut2 (red) mRNA expression by dual fluorescent in situ hybridization in the LH. Open arrows indicate Vglut2-expressing neurons. Solid arrows indicate Vgat-expressing neurons. B, C, Vgat in situ hybridization in the LH of Vgat flox/flox $(\boldsymbol{B})$ and Pdx 1 -Cre:Vgat ${ }^{\text {flox/flox }}$ mice $(\boldsymbol{C})$. D, Average number of Vgat-expressing neurons in Vgat ${ }^{\text {flox/flox }}$ and Pdx1-Cre:Vgat ${ }^{\text {flox/flox }}$ mice ( $n=3$ each). cp, Cerebral peduncle; f, fornix; mt, mammilothalamic tract; opt, optic tract; Zl, zona incerta. ${ }^{* *} p<0.01$, Student's $t$ test. Scale bars, 100 $\mu \mathrm{m}$.

\section{Results}

To examine the expression pattern of both Vgat and Vglut2 (also known as Slc32al and Slc17a6, respectively, required for presynaptic respective GABA and glutamate release) in the $\mathrm{LH}$, we performed dual-color in situ hybridization for both genes. We showed that both mRNAs were abundantly expressed in the LH (Fig. 1A). Importantly, none to few LH neurons coexpressed Vgat and Vglut2, indicating that GABAergic neurons and glutamatergic neurons are largely segregated in the LH (Fig. 1A). Although the role of glutamatergic LH neurons has been illustrated (Jennings et al., 2013), the function of GABAergic LH neurons in feeding regulation is, however, unclear.

We previously reported that Cre recombinase driven by the pancreas duodenum homeobox 1 promoter ( $\mathrm{Pdx} 1-\mathrm{Cre})$ is abundant in the $\mathrm{LH}$, the $\mathrm{DMH}$, the arcuate (Arc) and the preoptic area in the hypothalamus (Song et al., 2010). Importantly, in $P d x 1$ Cre:Vgat flox/flox mice, Vgat was largely deleted in throughout the LH (Fig. $1 B, C$ ) and was also reduced in other Pdx1-Cre expressing brain sites (data not shown). Based on the comparison of the Vgat expression pattern between controls and Pdx1-Cre: $V$ gat flox/flox mice, it appears that the LH regions with higher levels of Vgat expression showed more Vgat deletion (Fig. 1B,C). An estimate from matched LH sections from Vgat flox/flox and $P d x 1$ Cre: Vgat flox/flox mice ( $n=3$ each) showed that $\sim 80 \%$ LH GABAergic neurons expressed Pdx1-Cre (241 \pm 27 vs $49 \pm 7$ GABAergic neurons in the LH of Vgat flox/flox and Pdx1-Cre:Vgat flox/flox mice, respectively) (Fig. 1D). These data indicate that Pdx1Cre targets a major subset of GABAergic neurons in the LH. Thus, Pdx1-Cre mice, when combined with stereotaxic LH injections, allowed us to specifically target a major subset of GABAergic LH neurons.

To examine the physiological role of GABA release from $\mathrm{LH}$ GABAergic neurons, we aimed to disrupt GABA release from $\mathrm{LH}$ neurons by stereotaxically injecting adeno-associated viral vectors that express Cre (AAV-Cre-GFP) to the LH of Vgat flox/flox mice. To examine the efficiency of AAV-Cre-GFP in deleting the $V g a t$ gene, we stereotaxically delivered the Cre vector to one side of LH. Efficient Vgat deletion was validated by specific loss of Vgat mRNAs in the AAV-Cre-GFP infected area, compared with the other side of LH with intact Vgat expression (Fig. 2A,B). Based on post hoc analysis and the scoring criterion (see Materials

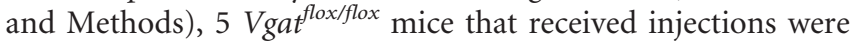
scored as hit (Fig. 2C-H). Vgat deletion in LH significantly reduced feeding and body weight at 3 weeks after injection (Fig.
$2 I, J)$, indicating that GABA release from $\mathrm{LH}$ neurons is required to maintain normal feeding.

To further illustrate the neural circuits that GABAergic LH neurons act upon to regulate feeding, we aimed to optogenetically stimulate these neurons using Pdx1-Cre expression in the LH. To selectively stimulate LH Pdx1-Cre neurons, we delivered Cre-dependent AAV-FLEX-ChR2-YFP vectors to the bilateral LH of Pdx1-Cre mice (Fig. 3A). As expected, YFP-expressing neurons were found selectively in the LH (Fig. $3 B-D)$. Interestingly, YFP-expressing fibers were not found in the anterior $\mathrm{PVH}$, but abundant in the posterior PVH (Fig. $3 E, F$ ). Upon laser stimulation of YFP-expressing fibers in the PVH, 10 of 12 posterior

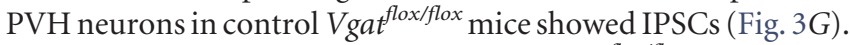
In contrast, 0 of 12 neurons in Pdx1-Cre:Vgat flox/flox mice exhibited IPSCs (Fig. 3G). These results support the existence of a GABAergic $\mathrm{LH} \rightarrow$ PVH circuit.

To examine the effect of photostimulation of YFP-expressing fibers in the PVH on feeding behavior, we implanted a fiberoptic directly above the posterior PVH (Fig. $3 H$ ). Low-intensity blue laser stimulation $(3 \mathrm{~mW})$ potently increased feeding during a 10 min photostimulation period in well-fed $P d x 1$-Cre mice (early morning) but had no obvious effect on feeding behavior in $P d x 1$ Cre:Vgat flox/flox mice (Fig. 3I). Notably, the distance between the tip of the fiberoptic and the closest LH Pdx1-Cre neurons was $\sim 1$ $\mathrm{mm}$, and $3 \mathrm{~mW}$ laser intensity used for feeding behavior, according to the estimation (the Deisseroth laboratory at Stanford University), will be reduced to $0.81 \mathrm{~mW} / \mathrm{mm}^{2}$ at $\mathrm{LH} \mathrm{Pdx1-Cre}$ neuronal soma, which is not sufficient to activate the neurons (Betley et al., 2013). These results, in conjunction with the previously observed hyperphagic GABA action in the PVH (Pu et al., 1999; Atasoy et al., 2012), indicate that activation of the GABAergic $\mathrm{LH} \rightarrow$ PVH circuit promotes feeding behavior.

Despite extensive studies on GABAergic input to the PVH (Cowley et al., 2001; Cole and Sawchenko, 2002; Kalra and Kalra, 2004; Atasoy et al., 2012), its function in feeding, especially in physiological conditions, remains unclear. For example, reduced GABAergic tone to PVH does not contribute significantly to hypophagia following AgRP lesions (Wu et al., 2009). In addition, loss of GABA release from AgRP neurons has no significant impact on the feeding behavior induced by AgRP neuron activation (Krashes et al., 2013), suggesting that GABA release from AgRP neurons is not the sole transmitter that mediates feeding behavior by AgRP neuron activation. To more precisely examine GABAergic input to the PVH, we disrupted GABAergic input to 

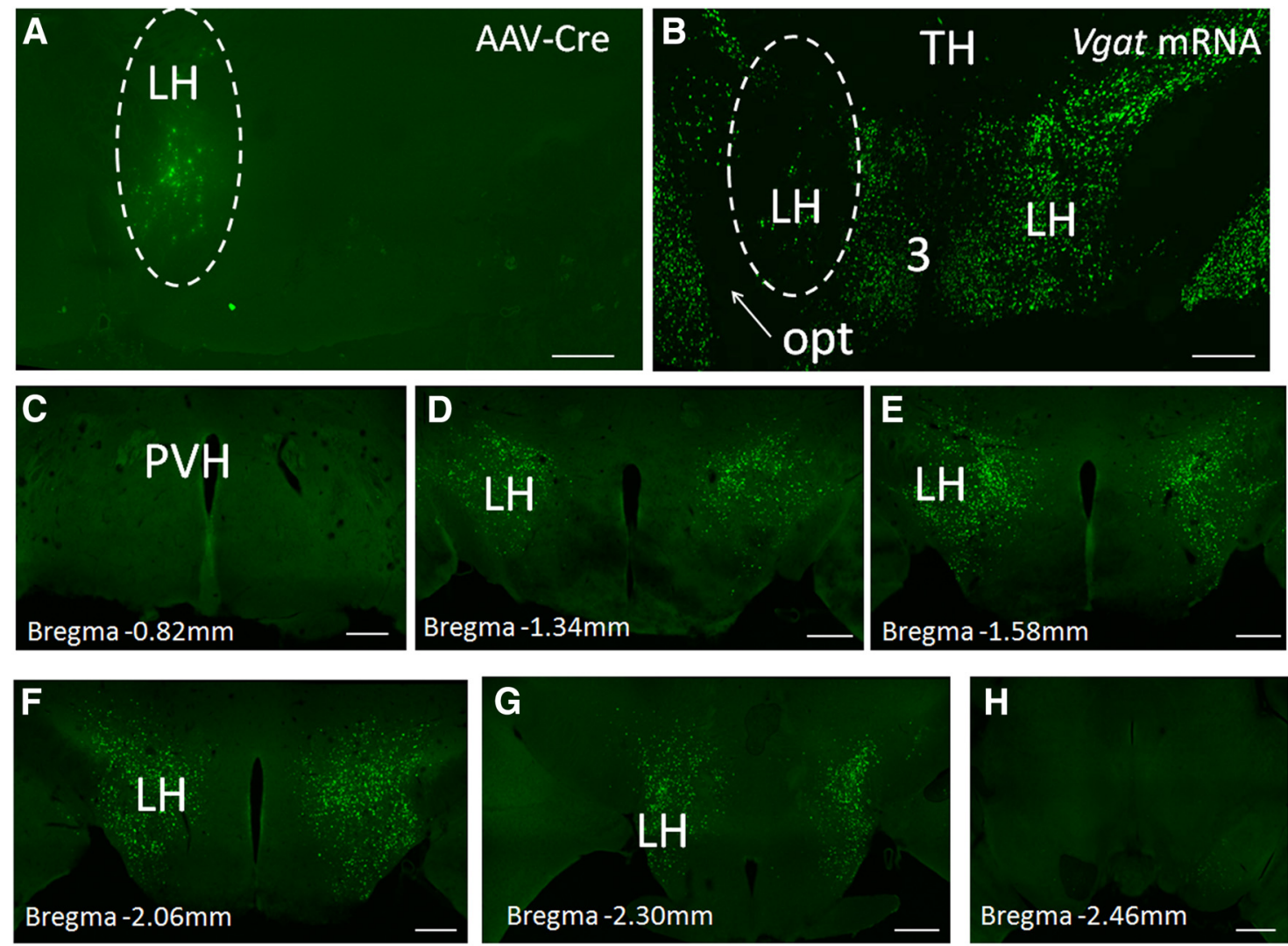

I

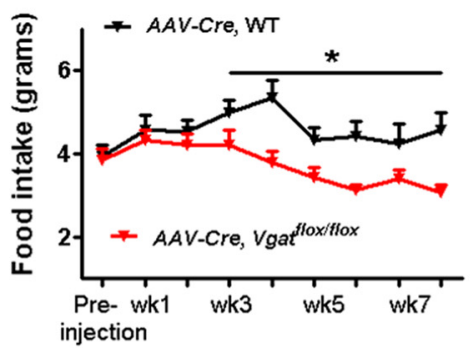

J

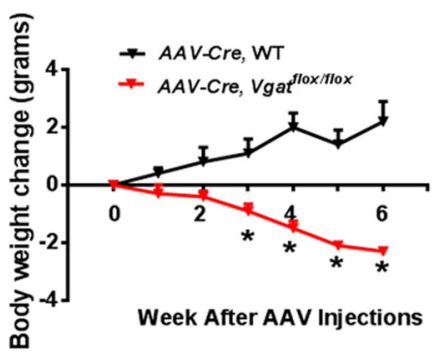

Figure 2. Deletion of Vgat in adult $L H$ neurons leads to reduced feeding. $\boldsymbol{A}, \mathbf{C}-\boldsymbol{H}$, GFP expression after AAV-Cre-GFP vector delivery to the brain. $\boldsymbol{B}$, In situ hybridization for Vgat in the

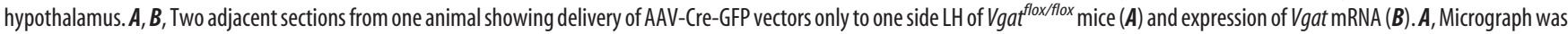
taken directly from sections freshly cut from frozen brains. White dashed line circle indicates the injected area. B, Micrograph showing sparsely distributed Vgat $m$ RNA on the injected side $L$ H (white dashed line circle) with AAV vector delivery, which was in contrast with the abundant $\mathrm{Vgat}$ mRNA on the opposite side, suggesting effective deletion of $V$ gat by AAV-Cre vectors. $\mathbf{C}-\boldsymbol{H}$, A representative case showing the expression profile of AAV-Cre-GFP vectors, from rostral to caudal levels as indicated by bregma levels, in the LH after stereotaxic delivery of the vectors to bilateral LH of Vgat floxfflox mice. A similar AAV-Cre injection profile was found in 4 other cases that were also scored as hit and peer-reviewed. $I, J$, Weekly food intake $(I)$ and changes in body weight $(\boldsymbol{J})$ measured for 8 weeks after AAV-vector injections. I, J, Data are mean \pm SEM; $n=5-8 .{ }^{*} p<0.05$ (unpaired Student's $t$ tests). LH, Lateral hypothalamus; 0 pt, optic tract; PVH, paraventricular hypothalamic nucleus; $T H$ thalamus. Scale bar, $250 \mu \mathrm{m}$.

the PVH by deleting $\gamma 2$ subunit of GABA-A receptors. Toward this end, we crossed Sim1-Cre mice with $\gamma 2^{\text {flox/flox }}$ mice to generate Sim1-Cre: $\gamma 2^{\text {flox/flox }}$ mice (Wulff et al., 2007; Xu et al., 2013). In these mice, $\gamma 2$ was largely deleted in the PVH (Fig. $4 A, B$ ), in the supraoptic nucleus and the nucleus of olfactory tract but was not obviously altered in other Sim1-Cre-expressing regions due to undetectable endogenous $\gamma 2$ expression levels (data not shown). To examine the consequence of $\gamma 2$ deletion on GABA-A receptors on PVH neurons, we performed whole-cell recording on PVH neurons in brain slices for GABA-A receptor-mediated currents IPSCs. Compared with control mice, evoked IPSCs in PVH neurons of Sim1-Cre: $\gamma 2^{\text {flox/flox }}$ mice were diminished (Fig. 4C-E), confirming that the function of GABA-A receptors was disrupted. Interestingly, Sim1-Cre: $\gamma 2^{\text {flox/flox }}$ mice showed reduced feeding (Fig. $4 F$ ), which was largely due to a specific reduction in nocturnal feeding (Fig. 4G). Thus, GABAergic input to PVH neurons promotes feeding, especially during the nocturnal period.

\section{Discussion}

Here we identify a novel direct GABAergic projection from the $\mathrm{LH}$ to the PVH that promotes feeding. This is the second group of hypothalamic GABAergic neurons, alongside AgRP neurons, that have been identified to elicit feeding (Fig. 4H). GABA release is not required for mediating AgRP neurons in promoting feeding (Krashes et al., 2013), whereas it is required for LH GABA neurons. Thus, unlike AgRP neurons, GABA is the sole transmitter that mediates the feeding behavior of the $\mathrm{LH} \rightarrow \mathrm{PVH}$ projection.

LH GABAergic neurons promote feeding, whereas glutamatergic ones inhibit feeding (Jennings et al., 2013), suggest- 
A

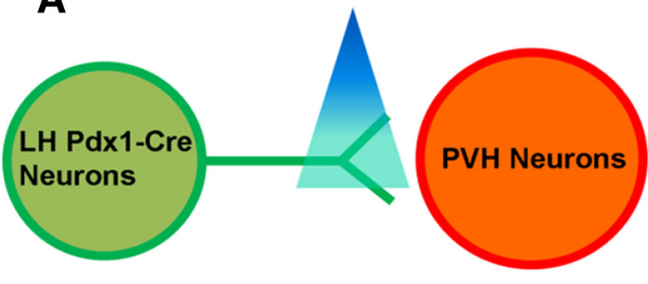

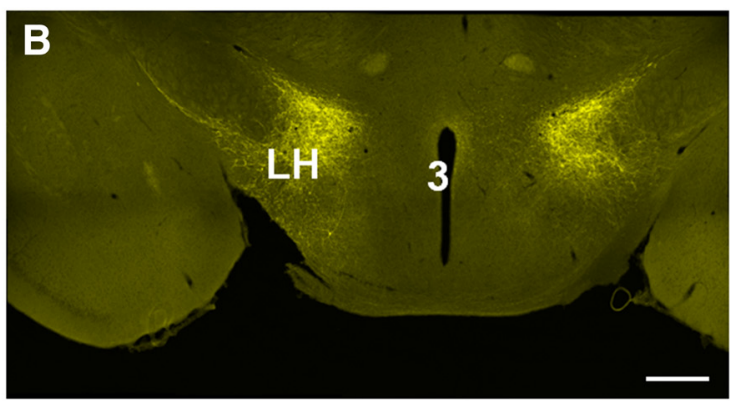
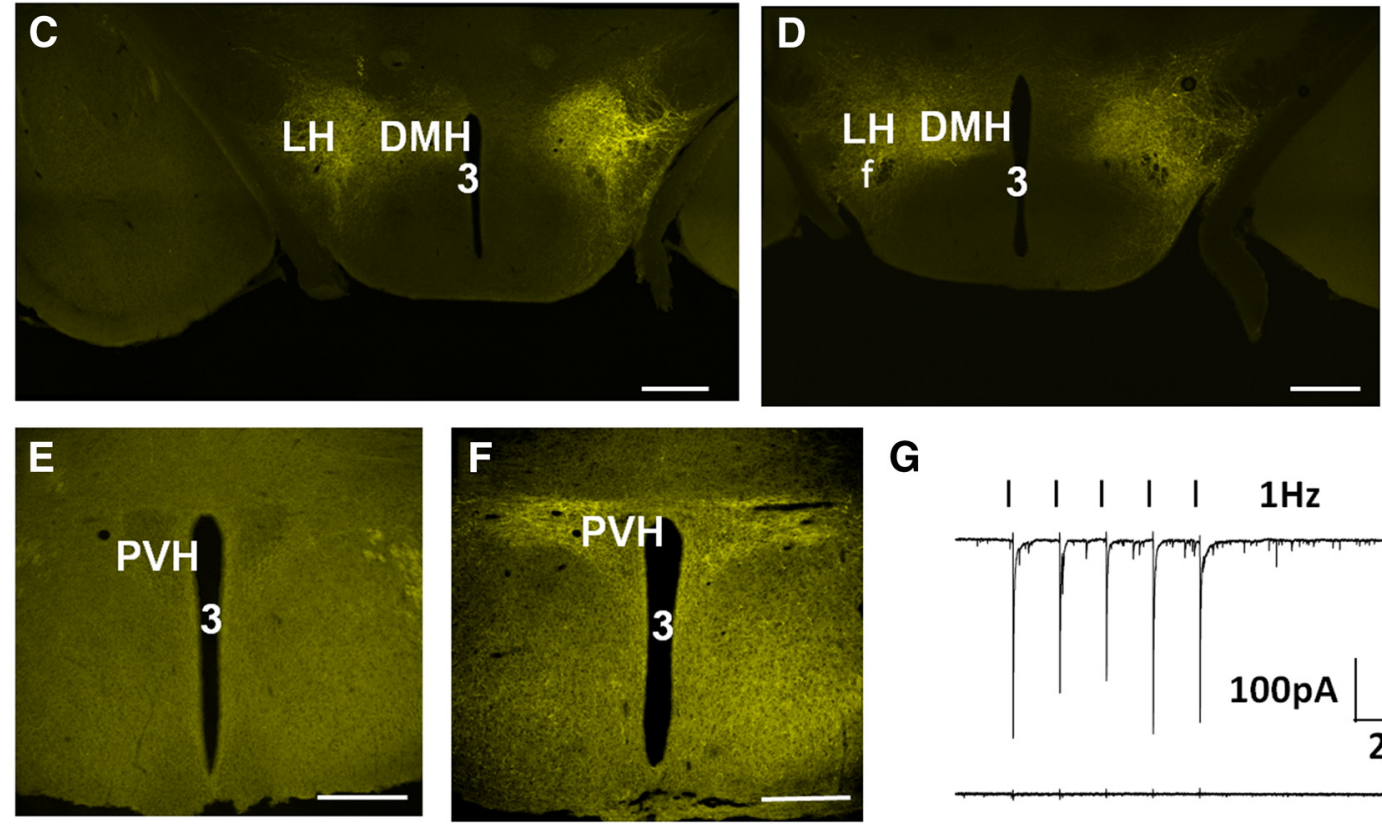

G

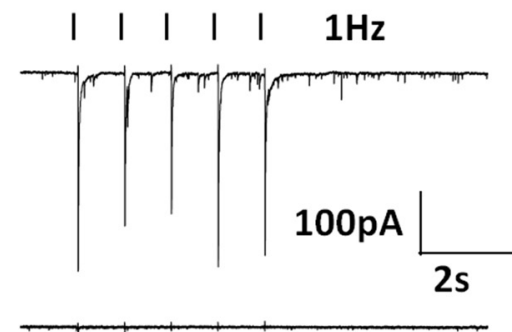

H

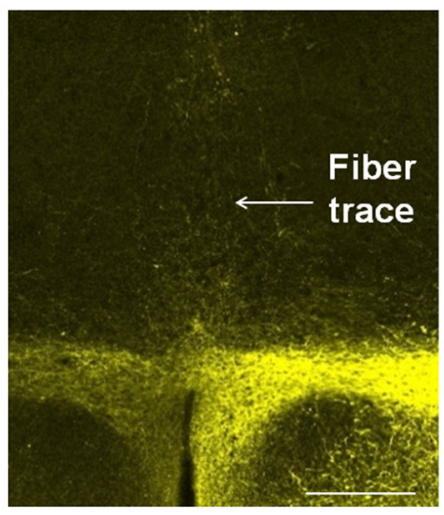

I

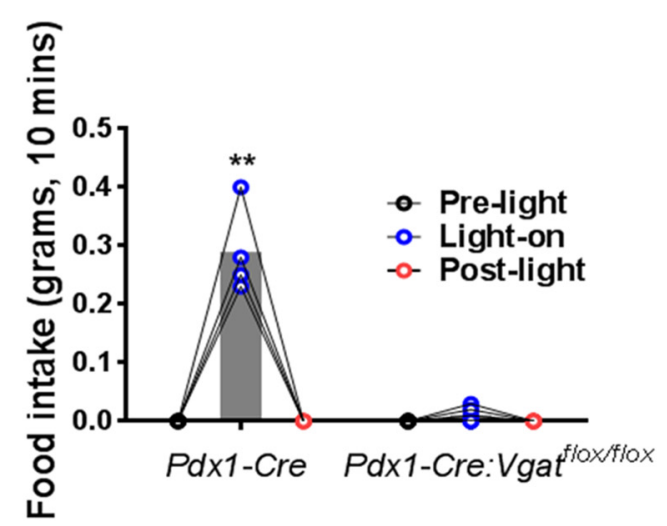

Figure 3. Optogenetic stimulation of GABAergic fibers from LH Pdx1-Cre neurons in the PVH promotes feeding in well-fed animals. A, Diagram showing ChR2-assisted circuitry mapping. $\boldsymbol{B}$ - $\boldsymbol{D}$, AAV-FLEX-ChR2-YFP expression pattern in bilateral LH of Pdx1-Cre mice at 2 weeks after viral delivery at the levels of bregma $-1.34 \mathrm{~mm}(\boldsymbol{B}),-1.46 \mathrm{~mm}(\boldsymbol{C})$, and $-1.58 \mathrm{~mm}(\boldsymbol{D})$. $\boldsymbol{E}, \boldsymbol{F}$, YFP-expressing fibers in the anterior $(\boldsymbol{E})$ and the posterior PVH $(\boldsymbol{F})$. G, IPSCs elicited by blue laser (black ticks) at $1 \mathrm{~Hz}$ in $P d x 1$-Cre (top) and Pdx 1-Cre:Vgat flox/flox mice (bottom). $\boldsymbol{H}, \mathrm{A}$ representative implantation of optic fiber cannula above the posterior PVH.I, Feeding response to laser stimulation during 10 min period in well-fed $P d x 1$-Cre and $P d x 1$-Cre:Vgat flox/flox mice. Data are mean \pm SEM; $n=4-6 .{ }^{* *} p<0.01$ (two-way ANOVA tests). 3, Third ventricle; DMH, ventromedial hypothalamus; LH, lateral hypothalamus; PVH, paraventricular hypothalamic nucleus. Scale bar, $250 \mu$ m.

ing divergent roles for LH neurons in feeding regulation. Lesions of LH cause hypophagia (Bernardis and Bellinger, 1996), suggesting that the effect of LH GABAergic neurons on feeding dominates over glutamatergic ones. Neurotensin and melanin-concentrating hormone $(\mathrm{MCH})$ neurons represent two known groups of LH GABAergic neurons. Because LH neurotensin neurons are activated by leptin to reduce food intake (Leinninger et al., 2011), it is unlikely that these neu- rons contribute significantly to the observed feeding promotion. Lesions of $\mathrm{MCH}$ neurons cause hypophagia and reduced body weight (Alon and Friedman, 2006), and MCH partially colocalizes with Pdx1-Cre expression in the LH (data not shown), suggesting that GABA release from $\mathrm{MCH}$ neurons might contribute to the feeding behavior. However, two recent studies with optogenetic stimulation of $\mathrm{MCH}$ neurons did not report any changes in feeding behavior (Domingos et al., 2013; 

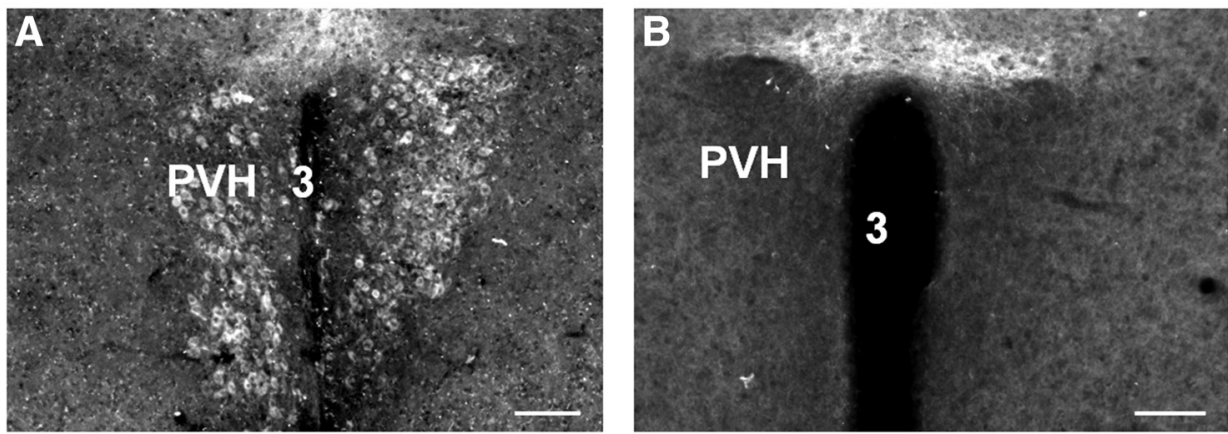

c

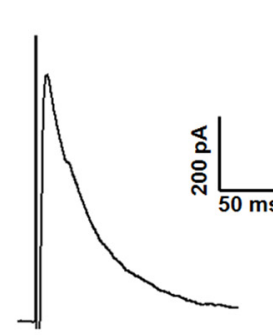

Y $2^{\text {flox/flox }}$

F

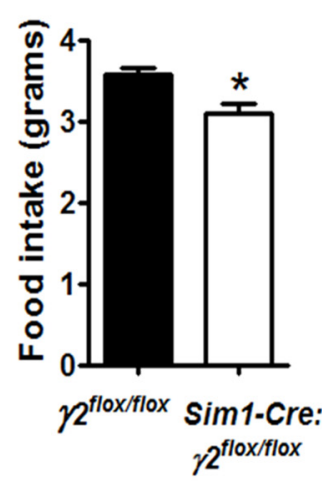

D

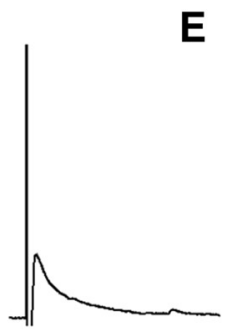

Sim1-Cre: $2^{\text {floxfflox }}$

G

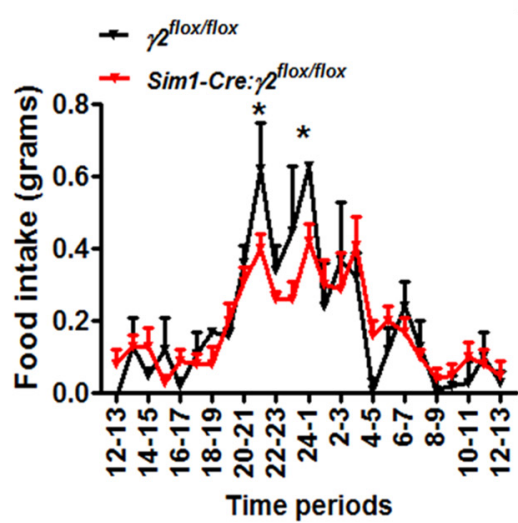

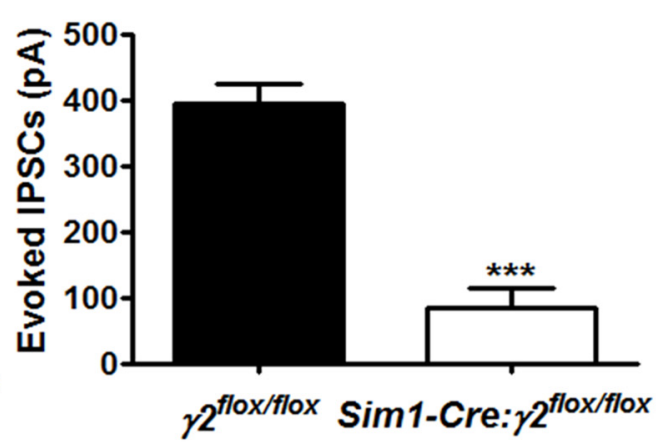

$\mathrm{H}$

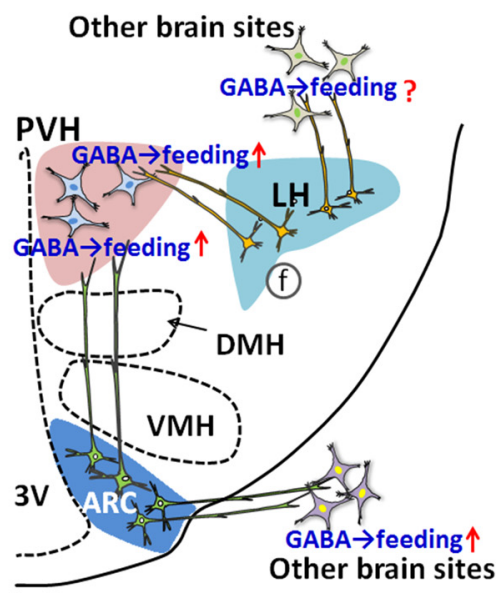

Figure 4. Deletion of GABA-A receptor $\gamma 2$ subunit in PVH neurons impairs GABAergic input and reduces feeding. $\boldsymbol{A}, \boldsymbol{B}$, Immunostaining of GABA-A receptor $\gamma 2$ subunit in $\gamma 2^{\text {flox/flox }}$ mice $(\boldsymbol{A})$ and Sim1-Cre: $\gamma 2^{\text {flox/flox }}$ mice (B). C, D, Representative traces showing evoked IPSCs in PVH neurons of $\gamma 2^{\text {flox/flox }}$ mice (C) and Sim1-Cre: $\gamma 2^{\text {flox/flox }}$ mice (D). $\boldsymbol{E}$, Statistical comparison of evoked IPSC amplitude between $\gamma 2^{\text {flox/flox }}$ mice and Sim 1-Cre: $\gamma 2^{\text {flox/flox }}$ mice. $\boldsymbol{F}$, Average daily food intake for each week during ages of $4-5 \mathrm{weeks}$ in males. $\mathbf{G}$, Hourly food intake measured for a period of $24 \mathrm{~h}$ at the age $6-7$ weeks. Data are mean \pm SEM; $n=19$ or $20(\boldsymbol{E})$ or $n=7$ or $8(\boldsymbol{F}, \boldsymbol{G}){ }^{*} p<0.05$ (unpaired Student's $t$ tests). ${ }^{* * *} p<0.001$ (unpaired Student's $t$ tests). $\boldsymbol{H}$, A summary diagram showing the role of GABAergic projections from LH to PVH in feeding promotion along with the known GABAergic projections from the arcuate nucleus to the PVH and other brain sites that also promote feeding. Whether $L H$ GABAergic projection to other brain sites also promotes feeding awaits further tests, as indicated by the question mark. 3V, Third ventricle; $\uparrow$, increased feeding; ARC, arcuate nucleus; DMH, ventromedial hypothalamus; f, fornix; LH, lateral hypothalamus; PVH, paraventricular hypothalamic nucleus; VMH, ventromedial hypothalamus.

Tsunematsu et al., 2014). Alternatively, a novel group of LH GABAergic neurons that are nonpeptdiergic is responsible for the observed feeding effects.

Disruption of GABA-A receptors in the PVH reduced feeding, which was largely due to reduced nocturnal feeding, suggesting an important role for GABAergic input to $\mathrm{PVH}$ in feeding regulation. Among various sources of GABAergic input to PVH neurons that are known to regulate feeding, GABAergic input from the Arc unlikely contributes significantly to the feeding defect because nearly complete deletion of Vgat in the Arc by Rip-Cre or Vgat deletion by AgRP-Cre causes no obvious feeding defects (Tong et al., 2008; Kong et al., 2012). Notably, GABA release from AgRP neurons is sufficient, but not required for feeding induced by AgRP neuron activation (Krashes et al., 2013). In addition, our preliminary data showed that AAV-Cre mediated deletion of
Vgat in the DMH led to no obvious changes in feeding (data not shown). Although it could not be ruled out that the GABAergic neurons outside LH contributed to the feeding defect observed in Sim1-Cre: $\gamma 2^{\text {flox/flox }}$ mice, given our results showing that disrupted GABA release from $\mathrm{LH}$ reduced feeding, it is likely that $\mathrm{LH}$ GABAergic neurons contribute significantly to the reduced feeding. Furthermore, a role for GABAergic $\mathrm{LH} \rightarrow \mathrm{PVH}$ pathway in nocturnal feeding is supported by the known role of the LH in arousal (Adamantidis and de Lecea, 2008), a state when mice normally feed. Together, our observations that LH GABAergic neurons provide monosynaptic inputs to PVH neurons, that photostimulation of LH GABAergic fibers in the PVH invokes GABA release-dependent feeding behavior, and that disruption of GABA-A receptors in the $\mathrm{PVH}$ reduced feeding strongly support a role for GABAergic $\mathrm{LH} \rightarrow$ $\mathrm{PVH}$ projections in promoting feeding. In summary, we have iden- 
tified a novel GABAergic projection from the $\mathrm{LH}$ to the PVH that is critical for feeding regulation, and our data support a physiologically important role for this circuit in nocturnal feeding.

\section{References}

Adamantidis A, de Lecea L (2008) Physiological arousal: a role for hypothalamic systems. Cell Mol Life Sci 65:1475-1488. CrossRef Medline

Alon T, Friedman JM (2006) Late-onset leanness in mice with targeted ablation of melanin concentrating hormone neurons. J Neurosci 26:389397. CrossRef Medline

Atasoy D, Betley JN, Su HH, Sternson SM (2012) Deconstruction of a neural circuit for hunger. Nature 488:172-177. CrossRef Medline

Balthasar N, Dalgaard LT, Lee CE, Yu J, Funahashi H, Williams T, Ferreira M, Tang V, McGovern RA, Kenny CD, et al. (2005) Divergence of melanocortin pathways in the control of food intake and energy expenditure. Cell 123:493-505. CrossRef Medline

Bernardis LL, Bellinger LL (1996) The lateral hypothalamic area revisited: ingestive behavior. Neurosci Biobehav Rev 20:189-287. CrossRef Medline

Betley JN, Cao ZF, Ritola KD, Sternson SM (2013) Parallel, redundant circuit organization for homeostatic control of feeding behavior. Cell 155: 1337-1350. CrossRef Medline

Cole RL, Sawchenko PE (2002) Neurotransmitter regulation of cellular activation and neuropeptide gene expression in the paraventricular nucleus of the hypothalamus. J Neurosci 22:959-969. Medline

Cowley MA, Smart JL, Rubinstein M, Cerdán MG, Diano S, Horvath TL, Cone RD, Low MJ (2001) Leptin activates anorexigenic POMC neurons through a neural network in the arcuate nucleus. Nature 411:480-484. CrossRef Medline

Domingos AI, Sordillo A, Dietrich MO, Liu ZW, Tellez LA, Vaynshteyn J, Ferreira JG, Ekstrand MI, Horvath TL, de Araujo IE, Friedman JM (2013) Hypothalamic melanin concentrating hormone neurons communicate the nutrient value of sugar. eLife 2:e01462. CrossRef Medline

Herman AM, Huang L, Murphey DK, Garcia I, Arenkiel BR (2014) Cell type-specific and time-dependent light exposure contribute to silencing in neurons expressing Channelrhodopsin-2. eLife 3:e01481. CrossRef Medline

Honig G, Liou A, Berger M, German MS, Tecott LH (2010) Precise pattern of recombination in serotonergic and hypothalamic neurons in a Pdx1cre transgenic mouse line. J Biomed Sci 17:82. CrossRef Medline

Jennings JH, Rizzi G, Stamatakis AM, Ung RL, Stuber GD (2013) The inhibitory circuit architecture of the lateral hypothalamus orchestrates feeding. Science 341:1517-1521. CrossRef Medline

Kalra SP, Kalra PS (2004) NPY and cohorts in regulating appetite, obesity and metabolic syndrome: beneficial effects of gene therapy. Neuropeptides 38:201-211. CrossRef Medline

Kong D, Tong Q, Ye C, Koda S, Fuller PM, Krashes MJ, Vong L, Ray RS, Olson DP, Lowell BB (2012) GABAergic RIP-Cre neurons in the arcuate nucleus selectively regulate energy expenditure. Cell 151:645-657. CrossRef Medline

Krashes MJ, Shah BP, Koda S, Lowell BB (2013) Rapid versus delayed stimulation of feeding by the endogenously released AgRP neuron mediators GABA, NPY, and AgRP. Cell Metab 18:588-595. CrossRef Medline

Krashes MJ, Shah BP, Madara JC, Olson DP, Strochlic DE, Garfield AS, Vong L, Pei H, Watabe-Uchida M, Uchida N, Liberles SD, Lowell BB (2014) An excitatory paraventricular nucleus to AgRP neuron circuit that drives hunger. Nature 507:238-242. CrossRef Medline

Kublaoui BM, Gemelli T, Tolson KP, Wang Y, Zinn AR (2008) Oxytocin deficiency mediates hyperphagic obesity of Sim1 haploinsufficient mice. Mol Endocrinol 22:1723-1734. CrossRef Medline

Leinninger GM, Opland DM, Jo YH, Faouzi M, Christensen L, Cappellucci LA, Rhodes CJ, Gnegy ME, Becker JB, Pothos EN, Seasholtz AF, Thompson RC, Myers MG Jr (2011) Leptin action via neurotensin neurons controls orexin, the mesolimbic dopamine system and energy balance. Cell Metab 14:313-323. CrossRef Medline

Luquet S, Perez FA, Hnasko TS, Palmiter RD (2005) NPY/AgRP neurons are essential for feeding in adult mice but can be ablated in neonates. Science 310:683-685. CrossRef Medline

Madisen L, Zwingman TA, Sunkin SM, Oh SW, Zariwala HA, Gu H, Ng LL, Palmiter RD, Hawrylycz MJ, Jones AR, Lein ES, Zeng H (2010) A robust and high-throughput Cre reporting and characterization system for the whole mouse brain. Nat Neurosci 13:133-140. CrossRef Medline

Melnick I, Pronchuk N, Cowley MA, Grove KL, Colmers WF (2007) Developmental switch in neuropeptide $\mathrm{Y}$ and melanocortin effects in the paraventricular nucleus of the hypothalamus. Neuron 56:1103-1115. CrossRef Medline

Paxinos G, Franklin KB (2004) The mouse brain in stereotaxic coordinates. Ed 2. San Diego: Elsevier Science.

Pu S, Jain MR, Horvath TL, Diano S, Kalra PS, Kalra SP (1999) Interactions between neuropeptide $\mathrm{Y}$ and gamma-aminobutyric acid in stimulation of feeding: a morphological and pharmacological analysis. Endocrinology 140:933-940. CrossRef Medline

Song J, Xu Y, Hu X, Choi B, Tong Q (2010) Brain expression of Cre recombinase driven by pancreas-specific promoters. Genesis 48:628-634. CrossRef Medline

Stanley BG, Urstadt KR, Charles JR, Kee T (2011) Glutamate and GABA in lateral hypothalamic mechanisms controlling food intake. Physiol Behav 104:40-46. CrossRef Medline

Tong Q, Ye CP, Jones JE, Elmquist JK, Lowell BB (2008) Synaptic release of GABA by AgRP neurons is required for normal regulation of energy balance. Nat Neurosci 11:998-1000. CrossRef Medline

Tsunematsu T, Ueno T, Tabuchi S, Inutsuka A, Tanaka KF, Hasuwa $\mathrm{H}$, Kilduff TS, Terao A, Yamanaka A (2014) Optogenetic manipulation of activity and temporally controlled cell-specific ablation reveal a role for $\mathrm{MCH}$ neurons in sleep/wake regulation. J Neurosci 34:6896-6909. CrossRef Medline

Wang F, Flanagan J, Su N, Wang LC, Bui S, Nielson A, Wu X, Vo HT, Ma XJ, Luo Y (2012) RNAscope: a novel in situ RNA analysis platform for formalinfixed, paraffin-embedded tissues. J Mol Diagn 14:22-29. CrossRef Medline

Wu Q, Boyle MP, Palmiter RD (2009) Loss of GABAergic signaling by AgRP neurons to the parabrachial nucleus leads to starvation. Cell 137:12251234. CrossRef Medline

Wulff P, Goetz T, Leppä E, Linden AM, Renzi M, Swinny JD, Vekovischeva OY, Sieghart W, Somogyi P, Korpi ER, Farrant M, Wisden W (2007) From synapse to behavior: rapid modulation of defined neuronal types with engineered GABAA receptors. Nat Neurosci 10:923-929. CrossRef Medline

Xu Y, Tong Q (2011) Expanding neurotransmitters in the hypothalamic neurocircuitry for energy balance regulation. Protein Cell 2:800-813. CrossRef Medline

Xu Y, Wu Z, Sun H, Zhu Y, Kim ER, Lowell BB, Arenkiel BR, Xu Y, Tong Q (2013) Glutamate mediates the function of melanocortin receptor 4 on Siml neurons in body weight regulation. Cell Metab 18:860-870. CrossRef Medline

Xu Y, O’Brien WG 3rd, Lee CC, Myers MG Jr, Tong Q (2012) Role of GABA release from leptin receptor-expressing neurons in body weight regulation. Endocrinology 153:2223-2233. CrossRef Medline 